\title{
The Complete Cycle To Achieve Industrial Energy Efficiency - Concept, Resources, And Application
}

Bin Wu, University of Missouri, Columbia, USA

\begin{abstract}
This paper discusses some of the key issues related to the institutionalization of best practice in industrial energy efficiency. It presents the structure and functionality of an integrated and computer-aided framework that logically supports the complete cycle of continuous energy efficiency improvement, the requirements of ISO 50001, and outlines some useful resources and tools developed to support the framework. Results of real life application involving over 100 manufacturing companies are also outlined.
\end{abstract}

Keywords: Energy Efficiency; Continuous Improvement; Computer-Aided Energy Audit; Web-Based ISO50001 Tool, Superior Energy Performance (SEP) Program

\section{INTRODUCTION}

he messages are simple:

- With increasing energy costs it makes business sense for a manufacturing organization to become energy efficient. The immediate impact of energy savings achieved by any company to its business wellbeing substantial: $\$ 1$ saved on the energy bill is a $\$ 1$ profit to the company, $100 \%$ and period. Therefore, $\$ 50,000$ a year in energy savings is really equal to $\$ 500,000$ a year in new sales of products and/or services, assuming an average profit margin of ten percent.

- $\quad$ Experiences show that there are still a lot of "low-hanging fruits" to be picked, requiring low level of investment and short payback period. For example, if a factory that uses a lot of compressed air, it does not require much of an investment to eliminate leaks in the system, but the payback potential is very high.

- $\quad$ To help reduce greenhouse emissions and be a responsible citizen, an industrial company needs to focus on ways to reduce the need for non-renewable energy sources, and increase the use of renewable energy sources and become energy efficient. There have been plenty of real life cases to support the claim that "energy efficiency is a source of energy" (Figure 1). Also, it is evident that many industrial corporations and companies have realized the importance of energy efficiency initiatives to their operation, both from an environmental and business point of view. 


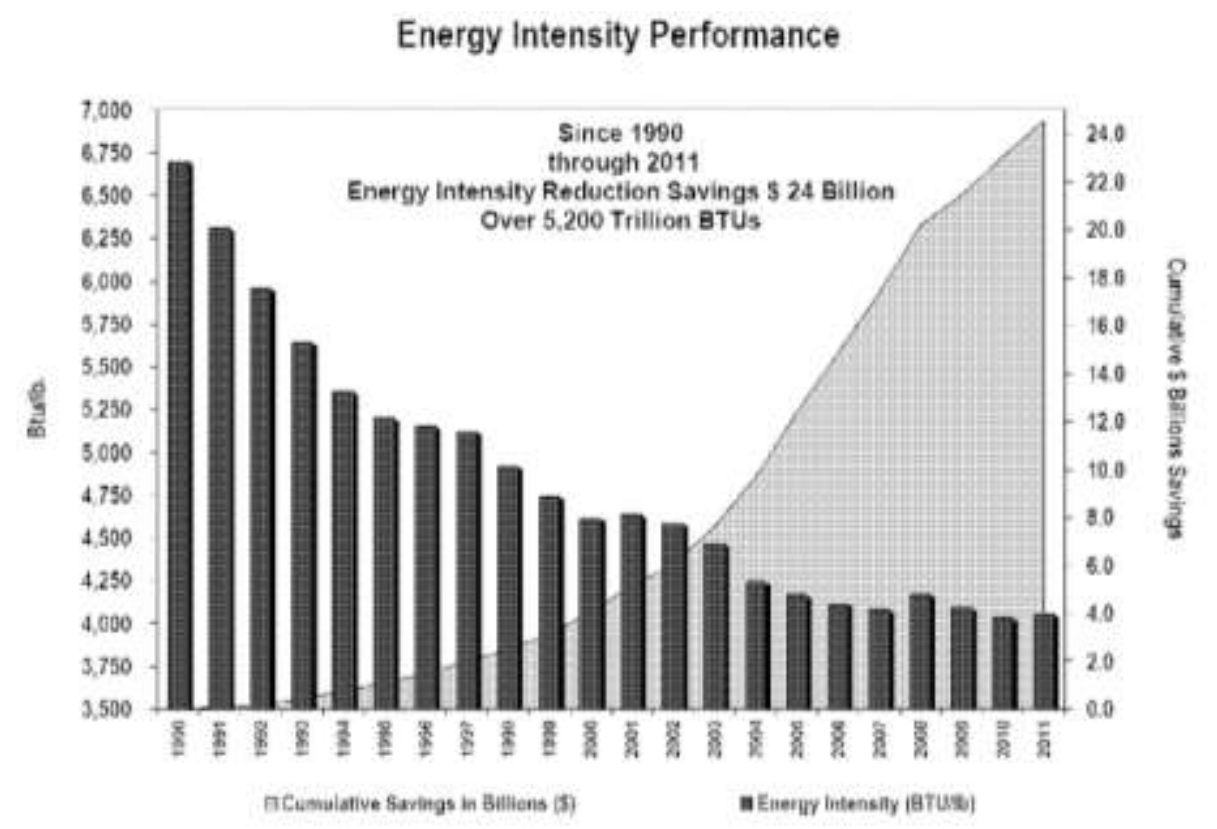

Figure 1 The case of Dow - one of the largest industrial groups in the world: significant reduction of global energy intensity (DOE 2012)

However, in reality companies are often faced with the following obstacles:

- $\quad$ Lack of in-house expertise or team, know-how, and resources to initiate and implement energy program

- Lack of effective methodology to help industrial organizations to plan, adopt and institutionalize energy efficiency solutions in their facilities

- $\quad$ Lack of institutionalized operational procedures and standard to set the energy efficiency program in the facilities

To help overcome the obstacles, a systematic approach is needed to help the industrial sectors to effectively initiate and implement an energy efficiency programs in a logical manner. Approaches and tools are needed by the industrial organizations to help tasks in the key areas:

- $\quad$ Education and training of personnel

- $\quad$ Planning and execution of energy efficiency projects: planning, data collection and analysis, identification of opportunities, detailing and justification of recommendations, implementation tasks

- Institutionalization of best practices in the organizational and operational structure: analysis and investigation of a organization's specific needs, identification of best practices guides and operational procedures, documentation

\section{The Key to Achieve Energy Efficiency: Continuous Cycle of Improvement}

In the industrial sectors, it is a well understood fact that a complete cycle is required to achieve continuous improvement of system performance: setting strategy and goals - analysis and design - implementation and operation, performance monitoring and setting of new goals (Wu, 2001, 2002). When related to the improvement of industrial energy efficiency, this cycle can be presented by a close-loop as shown in Figure 2. 


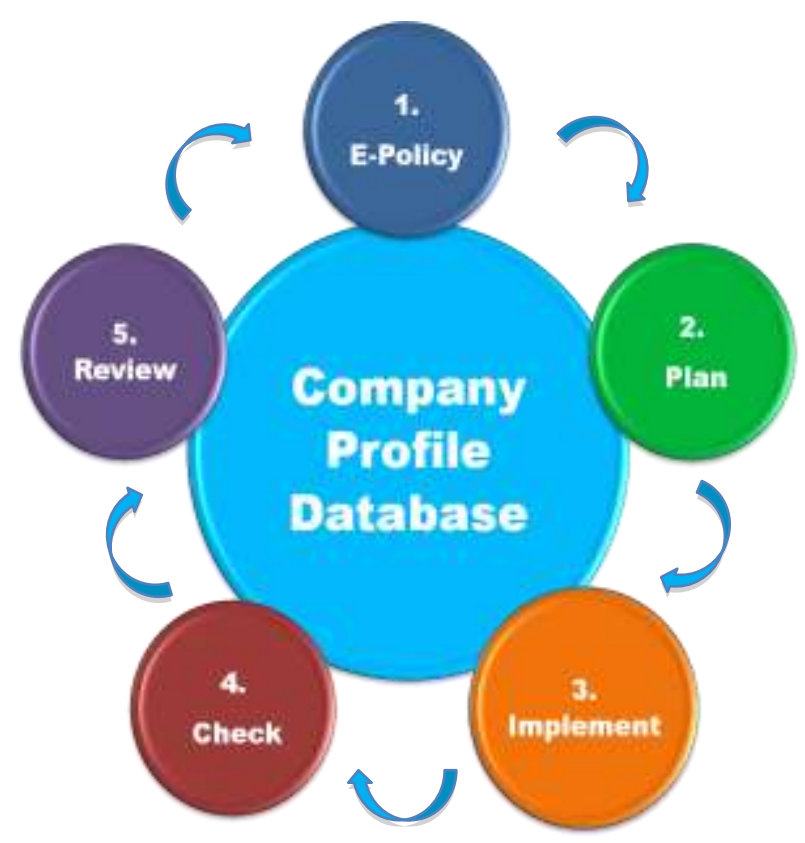

Figure 2 Complete cycle of continuous improvement of industrial energy efficiency: strategy, planning, implementation, monitoring

Here at Missouri Industrial Assessment Center (located at University of Missouri and supported by the U.S. Department of Energy), we have developed a task-centered approach to provide a framework to help achieving the above. The concept is based on the integration of all tasks to accomplish the work. These tasks may include tasks descriptions, instructions, processes, drawings, tools, data, etc. All elements, with the task-centered methodology, are integrated into one single platform. Within the web environment, this can be further enhanced by a web-based design in a focused way to provide good usability, so that the users can focus only on the tasks at hand and ignore the irrelevant contents and the system structure and navigation needs.

Since industrial energy efficiency analysis involves with a large number of documents and multitude of analysis and decisions, the concept of task-centered approach can be used as the basis for the development of a computer-aided workbook to incorporate energy audit procedures, processes, and tasks, following the life-cycle of an energy efficiency analysis. Following this approach, a computer-aided workbook have been developed and implemented to provide a complete guide to the processes, tasks and outcomes of an energy audit. From the initial audit planning to the final recommendation and follow-up, the workbook utilizes a front-end flowchart to specify the steps and tasks involved, and then logically integrate all the relevant entities such as instructions, data collecting tools, procedures of analysis and calculation, and worksheets to support task execution and project management. Other notable features include links to other resources, the experts/expertise database, and a specially developed worksheet for calculating organization-wide energy consumption. With the completion of the necessary steps, the workbook provides templates for generating final recommendations and report. In essence, it is a unified project tool that organizes and links instructional materials, worksheets, analytical tools, and resources in a logical and taskcentered manner. 


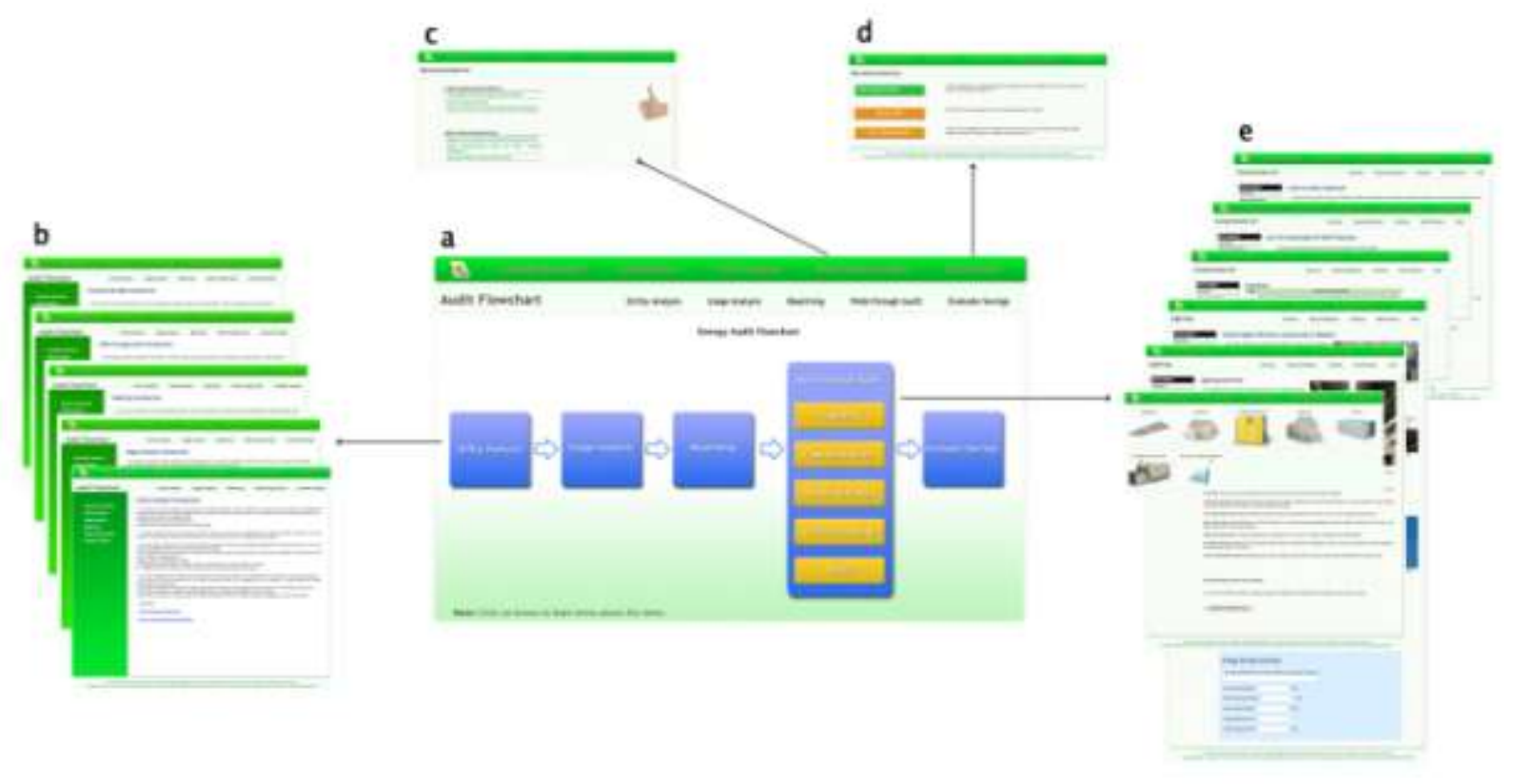

Figure 3 Web-based task-centered workbook: frontend and collections of "task documents"

A web-based implementation of this task-centered framework has been developed (Figure 3). It represents a knowledge base and project tool, in the form of a computer-aided "workbook". It provides a complete guide to the processes, tasks and outcomes of an industrial energy analysis. From the initial audit planning to the final recommendation and follow-up, the workbook should utilize a front-end flowchart to specify the steps and tasks involved, and then logically integrate all the relevant entities such as training materials and instructions, data collecting tools, procedures of analysis and calculation, and worksheets to support task execution and project management. In essence, it is a unified project tool that organizes and links instructional materials, worksheets, analytical tools, and resources in a logical and task-centered manner, as illustrated in the figure. As an integrated computer-aided training/application tool for industrial energy efficiency, it follows locally through the complete cycle of the energy improvement project, it is structured in a user-friendly and practical way to support:

- Interactive learning and training, by providing learning materials and best practice guides and resources in a focused way, for instance, see the figure. Each of the recommendations in the best practice list is supported by a task document that provides both theoretical details and tools.

- Application in actual energy improvement project through the provision of a collection of "task documents" that: (a) aid diagnosis and solution identification by providing on-line and up-to-date on-line checklist, and (b) help with the problem-solving tasks required through live tools for data collection, calculation and justification.

\section{DOE'S SOFTWARE TOOL SET}

Additionally, large amounts of information are readily available regarding the current technologies and general best practices. For example, a collection of software tools are provided on-line by the U.S. Department of Energy. They can be very useful tools to help companies to analyze their energy efficiency potentials in the typical energy consuming areas such as heating, steam, compressed air, motors, etc., as shown in Figure 4: 
ENERGY Exptomes

\section{Advanced Manufacturing Office}

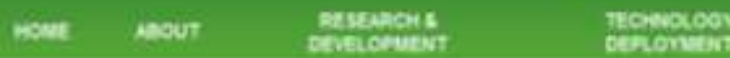

betronting

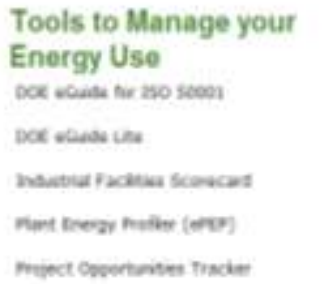

\section{Software Tool Updates}

A four port wobine series ased on tore boe bous and atort Aoril toth. The metinors will peovide monefacturens witt the information needed to sresorv lor implementing wh eneruy inanogement instien Energy inanogement in sopusted actwinties tied to the eceide. For more elormation, emo Coxily Sigaperence

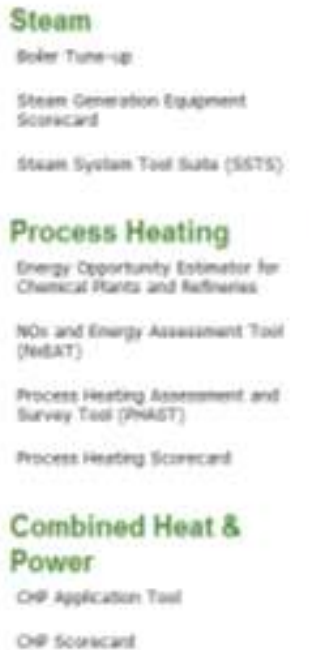

Fans

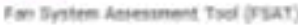

wo cotideter to fre

Data Centers

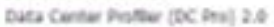

Motors

metoneaster

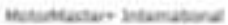

Solar

suppisen Tod

wates vikes

Neter New

Pumps

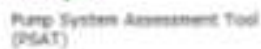

Manes scarveses

ved casuba sor hapa.
Other

$\mathrm{CO}_{2}$ Conderis

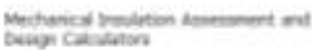

Nescus ciulns ne tutipestan Sorvent

Figure 4 Software tools provided by U.S. Department of Energy at: https://save-energy-now.org/EM/tools/Pages/HomeTools.aspx

These are sophisticate software tools that provide the ability to carry out detailed cost/benefit analysis of industrial energy saving projects, taking into account of technical, environmental and economic considerations. For instance, the following shows a screenshot of MotorMaster, which can be used by a company to:

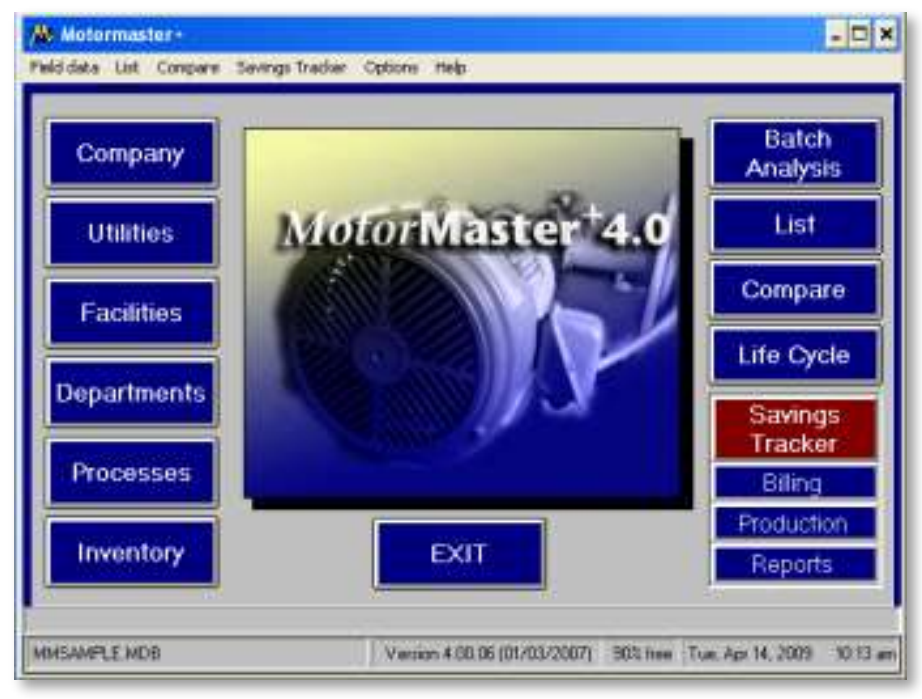

Figure 5 "MotorMaster" provided by U.S. Department of Energy at: https://save-energy-now.org/EM/tools/Pages/HomeTools.aspx 
- $\quad$ develop a profile of its current motor usage: models, locations and processes, and technical specification)

- $\quad$ analyze the motors' current operations: load, efficiency, etc.

- $\quad$ economic analysis: cost/benefits with replacement, re-winding, etc

\section{IAC DATABASE AND RECOMMENDATIONS}

The U.S. Department of Energy's Industrial Assessment Center (IAC) program keeps a useful database which provides statistical data based on thousands of industrial assessments. IAC's database is online at: http://iac.rutgers.edu/database/ .

It is particularly useful for a company to identify potential energy saving measures, by looking into historical cases according to types of industries and products.

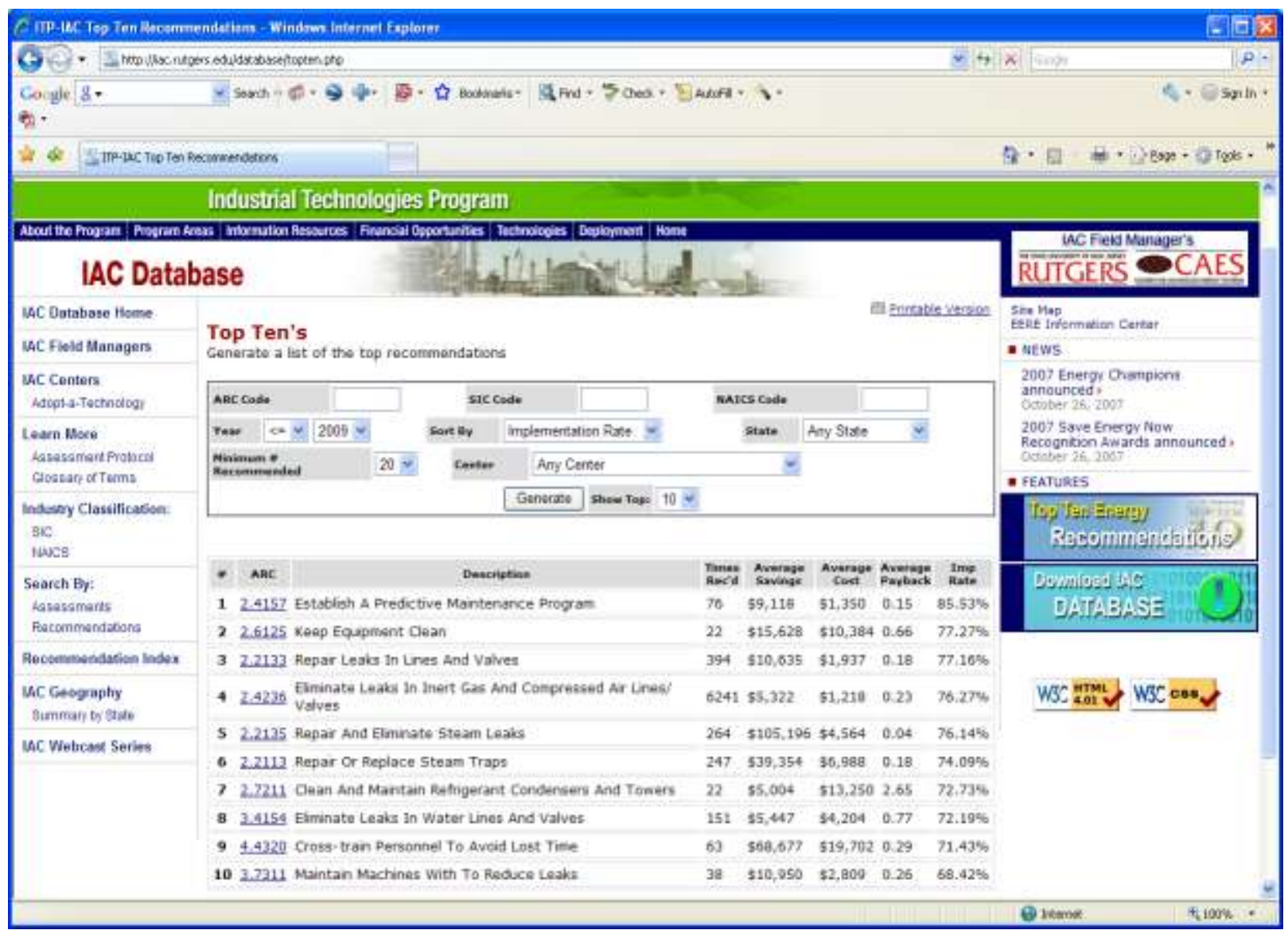

Figure 6 IAC Database

\section{CONTINUOUS IMPROVEMENT CYCLE, DOE SUPERIOR ENERGY PERFORMANCE (SEP) PROGRAM, AND ISO 50001}

The International Organization for Standardization (ISO) has developed a new set of standards addressing the use of energy in businesses: ISO50001:2011. This is an energy management system standard published by ISO on $9^{\text {th }}$ June 2011 and is an international framework that can be applied in companies for the efficient management of energy including its procurement and use (ISO 2012). Closely follow the concept of continuous improvement cycle, ISO 50001 proposes technical and management strategies for companies to follow so that energy use may be maximized and costs may be reduced. Experts estimate that this standard can influence up to $60 \%$ of the world's energy demand. 
The MoIAC web tool, as well as the other useful tools as outlined in the previous sections, provide useful tools to help the adaptation of this continuous improvement cycle. The DOE's tool set now contains one specifically designed for this purpose (Superior Energy Performance Program).

- Plan: Plan necessary objectives and action plans to integrate expected output of improved energy performance according to the organization's energy policy.

- Do: Implement the plan to collect necessary data for the purpose of generating possible solutions and analyzing the gap.

- Check: Check the actual results of the collected data in "Do" and compare them against the energy policy and objectives.

- $\quad$ Act: Act to apply changes that will continually improve energy performance and make sure the goals are met for your planning.

Our web tool, as outlined previously, is particularly relevant and useful for the Plan stage within this cycle. In addition, it is now expanded to provide the same task-centered support for all the tasks following the plan-docheck-act cycle.

It needs to be pointed out that a company the cycle of continuous improvement is "generic" in the sense that it follows the general principle of systems thinking and structured problem-solving. Also, getting certified with ISO50001 is NOT the necessary sole motive to adopt the cycle of improvement. It simply is a good tool to help implement and institutionalize good energy practice in an organization.

\section{ADAPTATION AND INSTITUTIONALIZATION - INDUSTRIAL CASES}

Together, the above provide a complete suite of framework and tools to help industrial companies adopt best practice in energy efficiency. Up to date, we have utilized such framework and tools to work with over 100 industrial companies located in the Midwest states of United States. The results in both potential identification, and actual implementation and savings (energy consumptions and utility costs) are significant in the majority of the cases.

As an example to illustrate the framework's potential as an effective means to help overcome the obstacles as previously identified, this case study outlines how the framework's structure and contents are being adapted by a manufacturing organization, and institutionalized within the organization to help the organization's global wide initiative of energy efficiency (Ponte 2011).

The industrial organization involved is one of the largest manufacturers in power and automation that employs approximately 117,000 people in over 150 companies based in 100 countries. Organizationally, as part of its effort to become green, the organization has established a global network of personals that consists of a global environmental advisor, a number of regional advisors and country advisors, and followed finally by factories environmental advisors who are located locally at each site.

It is realized that a key to improve the situation here is to have energy efficiency best practices institutionalized within its organizational and operational structures, and the structure and contents of the taskcentered framework provides an ideal platform to help the organization achieve this. It was therefore decided by the organization's leadership to adapt this framework and implement it within its global network of manufacturing companies as part of its standard operational procedures, to fill in the energy efficiency gap. In this case, the predicted benefits of the initiative are significant.

Up-to-date, the framework outlined in this paper has been used on six pilot sites within this organization.

\section{CONCLUSION}

According to the leadership in this initiative from the industrial organization as outlined above: "We're going to make energy-efficiency a part of the culture". 
For any industrial organization to adopt and institutionalize best practice in energy efficiency, there are obstacles to be overcome. This paper has described a cycle, together with relevant resources and tools, required to help an industrial organization to institutionalize best practices in energy efficiency. From strategic planning and implementation, to performance monitoring and continuous improvement, the conceptual framework follows a closed-loop that is designed to help companies elevate energy efficiency importance as a key part of the organization's strategic matrix, identify and adapt best practices, develop standardized operational procedures, implement the strategic and operational plans, establish monitoring mechanisms, and achieve continuous improvements.

\section{ACKNOWLEDGEMENTS}

The work reported here is funded by U.S. Department of Energy, through the Industrial Assessment Center Program, grant no. DE-EE0005529.

\section{AUTHOR INFORMATION}

Bin Wu is a professor of industrial engineering at University of Missouri. He is the founder and director of Missouri Industrial Assessment Center, one of the 24 IAC centers across the United States funded by the U.S. Department of Energy, as centers of education and services to help achieving industrial energy efficiency in the nation. E-mail: wubi@missouri.edu (Corresponding author)

\section{REFERENCES}

1. DOE (2012). http://www1.eere.energy.gov/manufacturing/pdfs/march_2012_webcast_for_industry.pdf , accessed on Aug 30, 2012

2. $\quad$ ISO/DIS 50001 (2012) Energy management systems - Requirements with guidance for use, 2010-08-16. International Organization for Standardization, Geneva, Switzerland

3. Ponte, S. (2011) "Achieving Energy Efficiency in Manufacturing: Organization, Procedures and Implementation", MSc thesis, University of Missouri, College of Engineering, May 2011.

4. Wu, B. (2001) “A Unified Framework of manufacturing Systems Design”, Industrial Management \& Data Systems, Volume 101 Number 9, pp 446-452, 2001.

5. Wu, B. (2002) Handbook of Manufacturing and Supply Systems Design: From Strategy Formulation to System Operation, Taylor and Francis, London (ISBN 0-415-26902-4), 2002. 